\title{
Natural Polymeric Film Encapsulating Propolis Nano-Formulation for Cutaneous Wound Healing
}

\author{
SIMONA CAVALU1*, PAULA MELANIA PASCA2*, MARCEL BROCKS* \\ 'University of Oradea, Faculty of Medicine and Pharmacy, 10, 1 Decembrie Sq., 410081, Oradea, Romania \\ 2University of Oradea, Doctoral School of Biomedical Sciences,10, 1 Decembrie Sq., 410081, Oradea, Romania
}

\begin{abstract}
The present paper describe the production and characterization of novel collagen films containing propolis encapsulated in chitosan nanoparticles, for biomedical applications such as cutaneous wound healing. Structural and morphological details were investigated by ATR FTIR spectroscopy, SEM and nanoindentation measurements, revealing the collagen fibers aligned in a quasi-parallel distribution, which might be favorable for biomedical applications. Moreover, the vibrational marker bands of propolis were well preserved in the final polymeric mixture, indicating the stability of bioactive compounds upon the encapsulation procedure. The antibacterial effect depends on the nanoparticles concentration in collagen film, the effect being more evident with respect to E. coli than S. aureus. The antioxidant capacity monitored by CUPRAC assay, indicated a synergic effect of chitosan nanoparticles matrix and propolis extract, incorporated in collagen films.
\end{abstract}

Keywords: collagen film, propolis, FTIR, SEM, antimicrobial effect

Wound healing is a complex process, chronic wounds typically taking longer than 3 months to heal, including different processes such as inflammation, epidermal restoration, wound contraction and remodeling. It has been demonstrated that platelets activation, cytokines secretion, macrophages, fibroblasts and keratinocytes are the most important active factors to promote wound closure and formation of new tissue [1]. Collagen is the mostabundant protein in the human body, playing a major role in the wound healing processes, as it is surface-active and capable of penetrating a lipid-free interface [2]. Previous studies demonstrated that exogenous collagen is more biocompatible than other natural polymers, being highly biodegradable, nontoxic, consisting of fibers with high tensile strength and stability via cross-linking and self aggregation $[3,4]$. Collagen-based wound dressings have long been used in the form of sheets, films and membranes, in wound healing and tissue engineering, to cover burn wounds and treat ulcers $[3,5-7]$. On the other hand, the blend of biopolymers, such as chitosan and collagen, have gained attention for successful and relevant applications as wound dressings due to their potentially beneficial biological properties, such as vehicles for the sustained release of pharmaceuticals, especially growth factors [8] or slow release of encapsulated drugs [9]. Chitosan is a good candidate for encapsulation, being widely used as a drug carrier for many possible routes of administration [10, 11], due to his non-toxicity, biocompatibility, biodegradability, and antibacterial activity. As a natural antibiotic, antifungal, antiviral and antiinflammatory agent, propolis extract can be used to improve some biological mechanisms involved in wound healing (e.g. epithelialization) [12]. Due to special phenolic compounds and high flavonoid content, which may vary according to the source and origin, propolis is a well known antimicrobial, but also recommended for his antioxidant activity [13]. Given the low sensitivity rates for commonly used antimicrobial agents and the occurrence of resistant multidrug strains, propolis nano-formulations might offer favorable alternatives to commonly used antibiotics [14, 15]. As presented in literature, the administration of phenolic and flavonoid compounds requires special formulation, with the aim to protect and maintain the structural integrity of the compounds, concomitant with the increase of its water solubility and bioavailability [16]. Micro and nano encapsulation techniques are available, using polymers of natural or synthetic origin, or lipids [17, 18] the resulted products being widely used in the food technology, pharmaceutical and cosmetic industries, biomedical and sensor industries. In the light of recent developments in the wound management field, the aim of our work was to prepare and to investigate the structural, morphological and antibacterial properties of novel collagen film with chitosan nanoparticles entrapping propolis extract, as an advanced and eco-friendly wound dressing device.

\section{Experimental part}

Production of collagen films with chitosan/propolis nanoparticles incorporated

Collagen type I from bovine Achilles tendon and chitosan (medium molecular weight, deacetylation degree $>75 \%$ ), were purchased from Sigma-Aldrich. Preparation of chitosan nanoparticles entrapping propolis extract was reported in our previous work [18], using an eco-friendly method. Briefly, a mixture of propolis extract and Arabic gum was added gradually, by vigorous stirring, to chitosan solution, and then, glutaraldehyde cross-linking agent was injected by syringe, under continuous stirring, allowing nanoparticles formation. The nanoparticles were separated from the suspension by centrifugation in vortex, at 4000 rpm, filtrated, washed with distilled water and freeze- dried. The obtained chitosan/propolis nanoparticles were characterized by DLS (Dynamic Light Scattering) and AFM (Atomic Force Microscopy), showing the maximum percentage of size distribution at around $120 \mathrm{~nm}$ (data not shown here).

In order to prepare the films, collagen was dissolved in $0.1 \mathrm{M}$ acetic acid solution to obtain a protein concentration of $2 \%(w / v)$. Collagen solution was completely solubilized by heating at $80^{\circ} \mathrm{C}$ for $30 \mathrm{~min}$, concomitant with magnetic stirring at $400 \mathrm{rpm}$. Finally, a precise quantity of powder chitosan/propolis nanoparticles was added to the collagen solution, respectively $100 \mu \mathrm{g} / \mathrm{mL}$ and $200 \mu \mathrm{g} / \mathrm{mL}$, by

\footnotetext{
* email: simona.cavalu@gmail.com; paula_pasca@yahoo.com physioempathie@gmail.com
} 
continuous stirring until homogenous mixture was obtained. The films were cast onto a glass plate and the solvent was volatized using compressed air jets, at room temperature. The films were kept in a sandwich system, between two glass plates, manually pressed.

Structural and morphological characterization of the films

The films were investigated by FTIR (Fourier Transform Infrared Spectroscopy) in the range $400-4000 \mathrm{~cm}^{-1}$, using Spectrum BXII spectrophotometer (Perkin Elmer), equipped with ATR accessory (ZnSe crystal), at scanning speed of $32 \mathrm{~cm}^{-1}$ and spectral width $2.0 \mathrm{~cm}^{-1}$. The morphological details of the films were observed by SEM (JEOL J SM7000F), for both the surface and cross-sectioned area. Collagen films with chitosan/propolis nanoparticles were also subjected to mechanical tests using the Nanoindenter G200 (Agilent Technologies, USA), at room temperature and normal humidity (45-52\%). The values of Young modulus were obtained from load-displacement curves, by fitting parameters, using Oliver-Pharr method [19].

\section{In vitro antimicrobial test}

Microorganisms Staphylococcus aureus (S. aureus ATCC 25923) -gram negative and Escherichia coli (E. coli ATCC 25922) -gram positive, were used for antimicrobial test, according to the agar diffusion method approved by Clinical and Laboratory Standards Institute [20]. The strains were cultivated in Luria-Bertani broth (LB broth) and after 18 hours, were transferred into Luria-Bertani agar (LB agar) used as culturing nutrient sources, in Petri dishes. The collagen/propolis films, in shape of small discs of $6 \mathrm{~mm}$ diameter, containing different nanoparticles concentration, respectively 100 and $200 \mu \mathrm{g} / \mathrm{mL}$, were placed on the agar plate, the antibiotic reference being a cellulose disk containing $10 \mu \mathrm{g}$ gentamycin. The inhibition of bacterial growth was determined by measuring the diameter of inhibition zones formed after $48 \mathrm{~h}$ of incubation.

In vitro antioxidant capacity by CUPRAC (Cupric ion reducing antioxidant capacity) assay

In order to assess the antioxidant effect of the polymeric mixture collagen/chitosan/propolis extract, the method
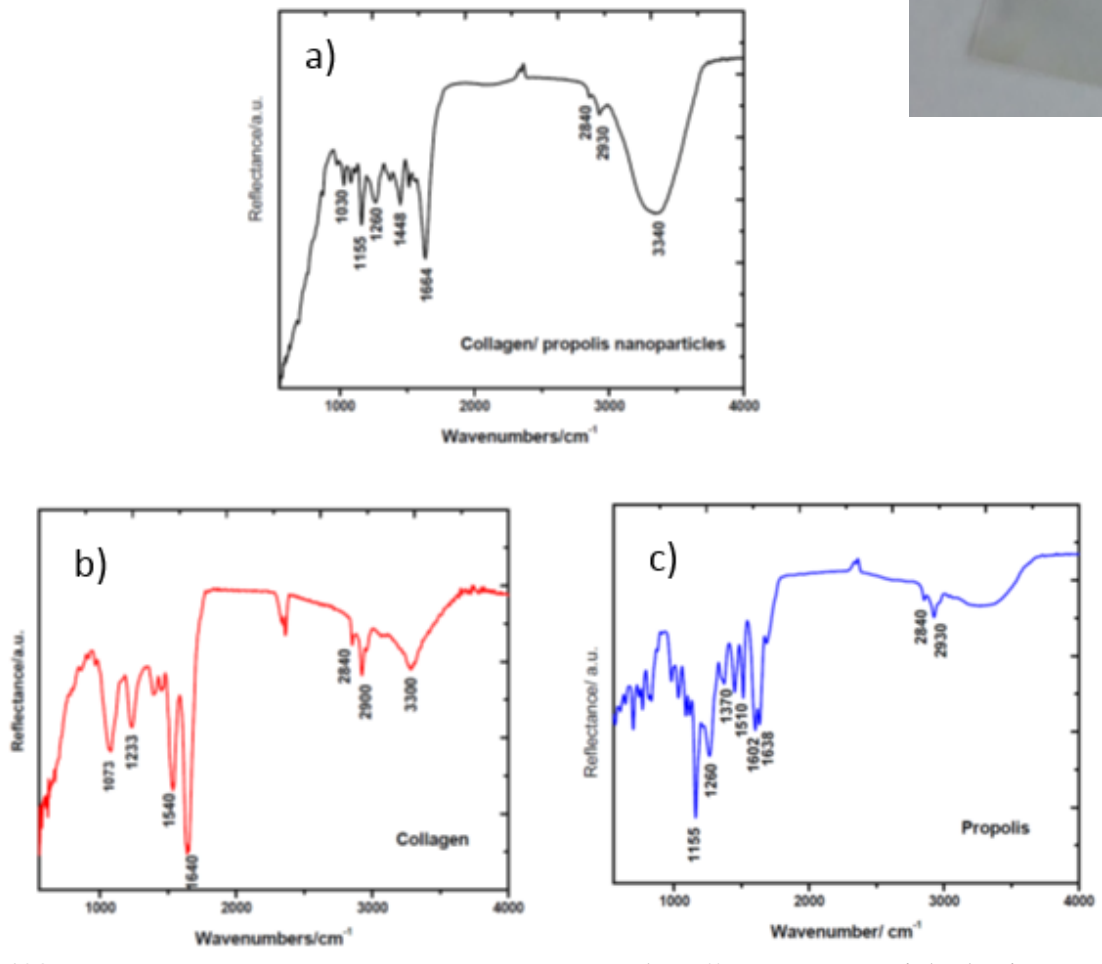

http://www.revmaterialeplastice.ro developed by Apak et al. [21, 22] was applied. The reagents Trolox, ammonium acetate, copper (II) chloride, ethanol, acetonitrile, PBS (phosphate buffer saline), neocuproine (2, 9-dimethyl-1,10-phenanthroline) were purchased from Sigma Aldrich Chemicals. Copper chloride solution $\left(\mathrm{CuCl}_{2} \cdot 2 \mathrm{H}_{2} \mathrm{O}\right) 1 \times 10^{-2} \mathrm{M}$ was prepared by dissolving 0.4262 $\mathrm{g}$ salt in water, and diluting to $250 \mathrm{~mL}$. Ammonium acetate buffer $(p H=7,1 M)$ was prepared by dissolving $19.27 \mathrm{~g}$ ammonium acetate in water and diluting to $250 \mathrm{~mL}$. Neocuproine solution $7.5 \cdot 10^{-3} \mathrm{M}$ was prepared by dissolving 0.039 g neocuproine in $96 \%$ ethanol. The CUPRAC assay for total antioxidant capacity was performed in a 96-well microplate, using spectrophotometric detection. To each well, $50 \mu \mathrm{L}$ of reagent solution were added in the following order: copper chloride solution ( $\left.1 \times 10^{-2} \mathrm{M}\right)$, neocuproine solution $\left(7.5 \cdot 10^{-3} \mathrm{M}\right)$ and ammonium acetate buffer solution $(p H=7.1 \mathrm{M})$. Finally, $100 \mu \mathrm{L}$ of each sample (collagen/chitosan/propolis polymeric mixture, propolis extract and chitosan solution) was added in a concentration of $10 \mathrm{mg} / \mathrm{mL}$. The calibration curve was obtained by using different concentrations of Trolox. The microplate was left to stand at room temperature for 30 min and the absorbance at $450 \mathrm{~nm}$ was recorded against a blank, using microplate reader Stat Fax 2100. The result was expressed as $\mu \mathrm{mol}$ Trolox equivalents (TE)/g.

\section{Results and discussions}

The gross appearance of collagen films with and without chitosan/propolis nanoparticles is presented in figure $1(a, b)$, showing their transparency in both cases. The structural characteristics of collagen films, with and without chitosan/propolis nanoparticles are presented in figure 2, along with the characteristic fingerprint of raw propolis.

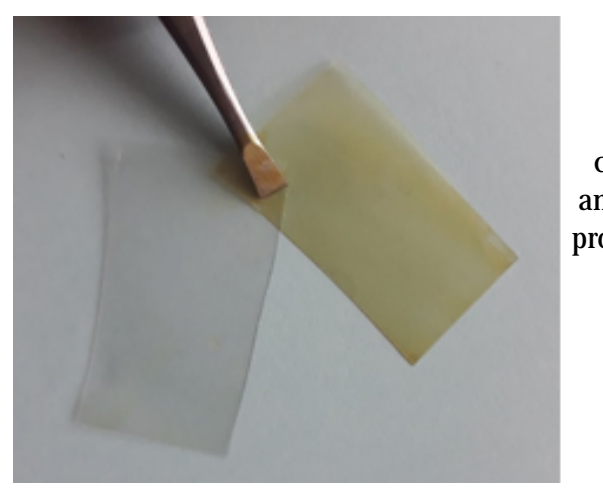

Fig. 1 The gross appearance of collagen films with and without chitosan/ propolis nanoparticles incorporated
Fig. 2 ATR-FTIR spectra of the samples: a) collagen film with chitosan/propolis nanoparticles incorporated ; b) collagen film without propolis; c) raw propolis, as purchased from the supplier. 
The vibrational fingerprint of propolis can be observed in the high wavenumber region as a doublet at 2840/2930 $\mathrm{cm}^{-1}$ assigned to stretching vibrations of $\mathrm{C}-\mathrm{H}$ bonds in $\mathrm{CH}_{2}$ and $\mathrm{CH}_{3}$ groups, and in the lower wavenumber region, as a doublet at $16388 / 1602 \mathrm{~cm}^{-1}$ assigned to $\mathrm{C}=0$ stretching vibrations in flavonoids and lipids. The most intense band $\left(1155 \mathrm{~cm}^{-1}\right.$ ) and the medium one at $1260 \mathrm{~cm}^{-1}$ are due to the vibrations of $\mathrm{C}-\mathrm{O}$ and $\mathrm{C}-\mathrm{OH}$ bonds in polyols (such as hydroxyflavonoids), while some weak vibration modes, at about $1510 \mathrm{~cm}^{-1}$, are assigned to aromatic ring deformations and $\mathrm{C}-\mathrm{H}$ vibrations, according to the literature $[23,24]$. Collagen membrane displayed mainly the characteristic bands at 1640,1540 and $1233 \mathrm{~cm}^{-1}$, attributed to amide I, II and III bands, respectively. Generally, amide $\mathrm{I}$ bands originated from $\mathrm{C}=0$ stretching vibrations coupled to $\mathrm{N}-\mathrm{H}$ bending vibrations, amide II bands occurs from the $\mathrm{N}-\mathrm{H}$ bending coupled with $\mathrm{C}-\mathrm{N}$ stretching vibrations, while amide III represent the combination between $\mathrm{N}-\mathrm{H}$ deformation and $\mathrm{C}-\mathrm{N}$ stretching vibrations [25]. The band at $1073 \mathrm{~cm}^{-1}$ arise from C-O-C absorptions of carbohydrate moieties. In the high wavenumber region, absorptions from amide $A$ and $B$, at $3300 \mathrm{~cm}^{-1}(-\mathrm{OH}$ bending) and $2900 \mathrm{~cm}^{-1}$ (NH stretching) can be observed. The FTIR spectrum of the blend film shows the same characteristic bands of the parent molecules, with small changes. First of all, it has to be noticed that the marker bands of propolis are well preserved in the final polymeric mixture, indicating that the bioactive compounds are stable upon the encapsulation procedure. On the other hand, as a result of the incorporation of chitosan/propolis nanoparticles in the collagen films, the characteristic bands of collagen (amide I and II) were both redshifted and the intensity of the peaks also changed, indicating that a hydrogen bond was formed between the chitosan and collagen molecules. In the same time, the large band at about $3340 \mathrm{~cm}^{-1}$ in the mixt film, become more intense and stiffened, also suggesting the hydrogen bonding between chitosan and collagen molecules. The explanation is based on the electrostatic interaction between the positively charged $\mathrm{NH}^{3+}$ in chitosan and the negatively charged $\mathrm{COO}^{-}$in collagen [26]. According to literature, another explanation of spectral differences among the films (with or without chitosan/propolis nanparticles) can be attributed to intermolecular interactions, variable conformation and molecular orientation of protein and polysaccharide chains [27].

The morphological details of collagen film with chitosan/ propolis nanoparticles incorporated are presented in figure 3 , showing the electron microscopy images recorded on the surface and cross-section of the collagen film with chitosan/propolis nanoparticles incorporated. One can observe a network of collagen fiber bundles, quasiorientated on the surface, with an overall parallel alignment. On cross section, a very dense and compact structure, well-aligned collagen fibers, in a multilayered lamellar structure is observed. Usually, collagen fibers in different films formulation, prepared by film casting, electrodeposition method or electrospinning, are randomly orientated [28, 29]. In our formulation, as a result of rapid solvent volatilization under compressed air jets, followed by the manual pressing in a sandwich system, the collagen fibers are aligned in a quasi-parallel distribution, which might be favorable for biomedical applications [30].

The nano-mechanical properties of collagen film incorporating chitosan/propolis nanoparticles were investigated as load-displacement curves and fitting parameters in order to obtain the value of Young modulus. In order to evaluate the nano-mechanical properties of

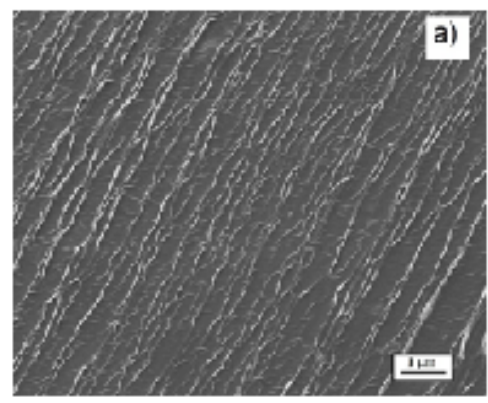

Fig. 3 SEM images recorded on the surface (a) and cross-section (b) of collagen film with chitosan/propolis

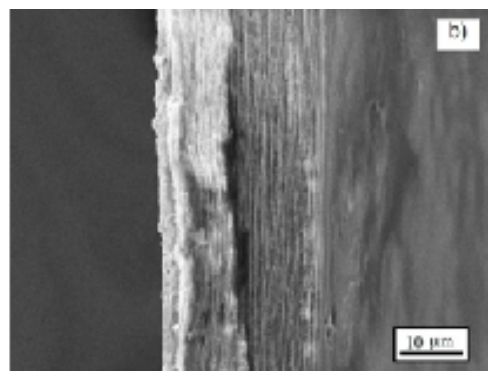

nanoparticles incorporated

collagen film with chitosan/propolis nanoparticles, the load-displacement profile is displayed in figure 4 . The nanoindentation test was repeated five times in order to obtain accurate results. One can observe that a maximum load of $20 \mathrm{mN}$ was necessary to reach a displacement of $2.8 \mu \mathrm{m}$. The average value of the Young modulus obtained from load-displacement curves, by fitting parameters, was $\mathrm{E}=4.5 \pm 0.2 \mathrm{MPa}$. Comparing the result with similar studies in literature, we noticed a dependence of Young's modulus on the percentage of chitosan in collagen/chitosan blend. For example, Sionkowska et. al [31] found a Young's modulus value of $2 \div 3 \mathrm{MPa}$ when the percentage of chitosan vary from $20 \%$ to $60 \%$ in the blended film. In the same time, they demonstrated that Young's modulus of collagen/chitosan films with different ratio was much higher than Young's modulus for collagen films or chitosan films unmodified. Ratiu et al. [8] investigated the modifications of resorbable collagen membranes for guided bone regeneration, upon addition of plasma rich in growth factors (PRGF). They concluded that the changes in Young modulus values are correlated with the ultrastructural properties of each membrane type, more precisely the porosity; the higher the porosity, the lower the Young modulus value was obtained. After the PRGF treatment, the nanoindentation measurements indicated the Young modulus value ranging in the interval $2.8-4 \mathrm{GPa}$, depending on the type of the membrane [8].

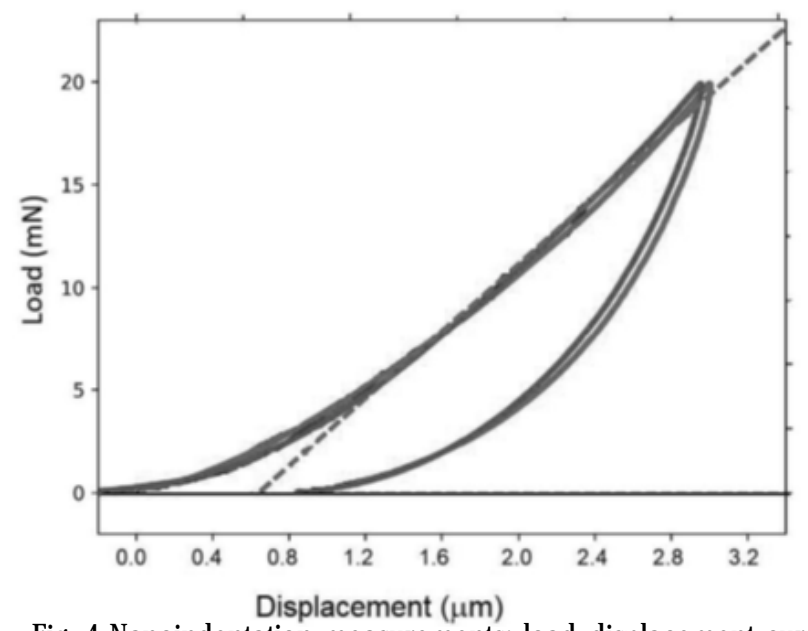

Fig. 4 Nanoindentation measurements: load-displacement curves recorded for collagen membrane with chitosan/propolis nanoparticles incorporated. 

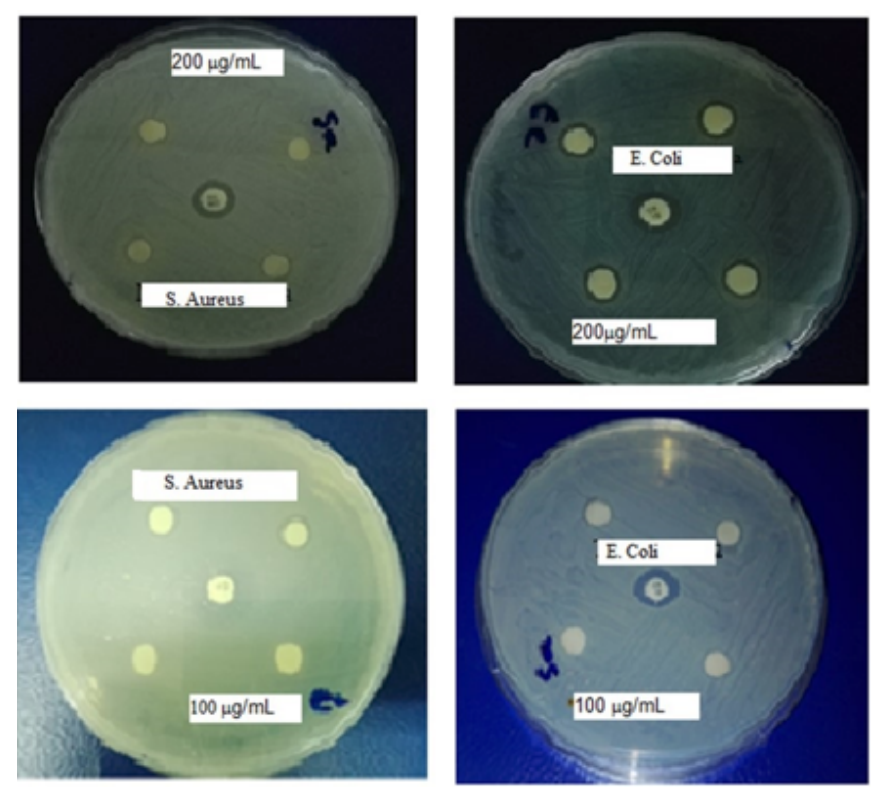

Fig. 5 Agar discs and showing inhibition zone diameter of collagen films incorporating different concentration of chitosan/propolis nanoparticles (100 respectively $200 \mu \mathrm{g} / \mathrm{mL}$ ) tested against $S$. aureus and Escherichia coli.
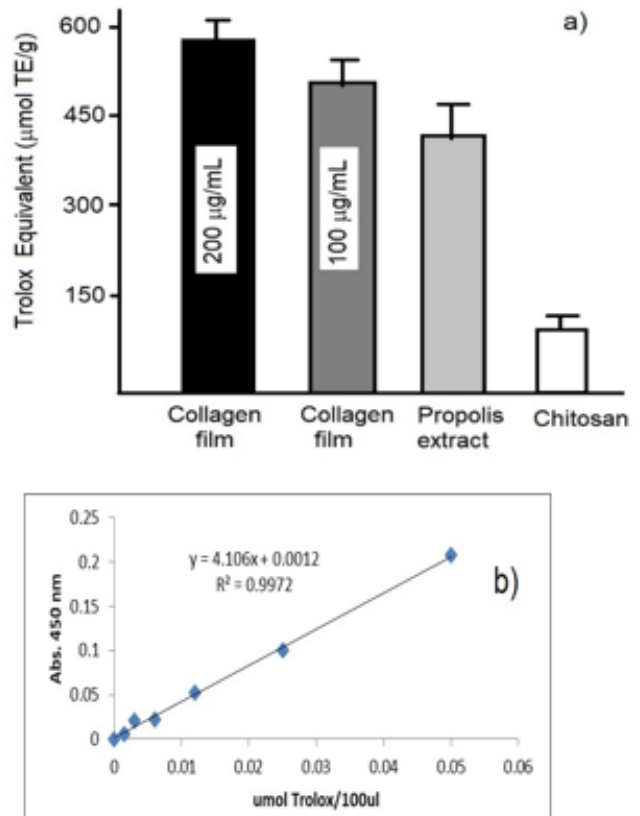

Fig. 6 a) The antioxidant capacity of the collagen film with chitosan/ propolis nanoparticles incorporated (in concentration of 100 respectively $200 \mu \mathrm{g} / \mathrm{mL}$ ) using CUPRAC; b) The calibration curve using Trolox as antioxidant standard

\begin{tabular}{|c|c|c|}
\hline $\begin{array}{c}\text { Concentration of chitosan/propolis } \\
\text { nanoparticles incorporated } \\
\text { in collagen film }\end{array}$ & $\begin{array}{c}\text { S. cureus } \\
\text { (diameter } / \mathrm{mm}=\mathrm{SD} \text { ) }\end{array}$ & $\begin{array}{c}\text { E. coli } \\
\text { (diameter } / \mathrm{mm} \pm \mathrm{SD} \text { ) }\end{array}$ \\
\hline $100 \mu \mathrm{gg} / \mathrm{mL}$ & $8.2 \pm 0.25$ & $9.1 \pm 0.32$ \\
\hline $200 \mu \mathrm{g} / \mathrm{mL}$ & $8.7 \pm 0.30$ & $10.2 \pm 0.10$ \\
\hline
\end{tabular}

Table 1

DIAMETER OF INHIBITION ZONE MEASURED IN PETRI DISHES (RESULTS ARE EXPRESSED AS MAIN VALUE \pm STANDARD DEVIATION)

One can observe that antibacterial effect depends on the nanoparticles concentration in collagen film, for both bacteria investigated. By comparison, the effect is more evident with respect to $\mathrm{E}$. coli than $\mathrm{S}$. aureus. The pharmacological activities with respect to biological, physiological, and medicinal benefits of propolis have been extensively studied and reported in many studies [23, 32, 33]. According to previously reported results [7], the antibacterial activity of propolis is greater against Grampositive bacteria owing to the presence of flavonoids, acids, and aromatic esters on its composition, similar results being obtained with Brazilian red propolis [32] suggesting that the inhibitory effect represent the synergistic effect between phenolic acids, flavonoids, pinocembrin and galangin, which are the most prominent bioactive compounds in propolis. However, the variation in the microbiological results between different reports in literature, can be explained by the influence of some factors related to the propolis extraction technique or geographical origin and flora diversity [33].

In order to assay the total antioxidant capacity of collagen films with different concentration of chitosan/ propolis nanoparticles incorporated, compared with propolis extract and chitosan, CUPRAC assay was employed, based on the advantages of this method over other similar assays. The CUPRAC reagent is fast enough to oxidize thiol-type antioxidants, being selective, more stable and accessible than other chromogenic reagents. Another advantage of this method is the possibility to simultaneously measure hydrophilic and lipophilic antioxidants [22]. The results are presented in figure 7a by comparing the antioxidant capacity of collagen films incorporating different concentration of chitosan/propolis nanoparticles (100 respectively $200 \mu \mathrm{g} / \mathrm{mL}$ ), with propolis extract and chitosan polymeric matrix used in the fabrication process of nanoparticles [18]. The calibration curve is also presented in Fig.7b, showing a very good correlation coefficient $\left(R^{2}=0.9972\right)$. As expected, the antioxidant capacity is dependent on the concentration of propolis extract encapsulated in chitosan nanoparticles, and moreover, both concentrations shows a better activity compared to free propolis extract. Also, chitosan matix (alone) shows a significant antioxidant capacity, and so, the overall process is the result of synergic effect of chitosan matrix and propolis encapsulated in chitosan nanoparticles. Of course, due to the high molecular complex composition of propolis, different extractive processes and various solvents used to solubilize the extracted polyphenols from propolis, may influence the biological properties of final product. Comparing with other studies reported in literature, our results indicates that collagen films prepared in our study possess biological properties suitable for cutaneous wound healing [34].

\section{Conclusions}

We have successfully prepared collagen films incorporating chitosan/propolis nanoparticules for possible cutaneous wound healing applications. The ATR-FTIR analysis demonstrated the preservation of propolis bioactive compounds in the structure of collagen films and the stability of the films, based on the balanced crosslinking toward electrostatic interaction. The microstructure and morphological features of the films revealed a network of collagen fiber bundles, quasiorientated on the surface and overall parallel alignment. A very dense and compact structure, well-aligned collagen fibers, in a multilayered lamellar structure was observed on cross section. The nanoindentation testindicated a Young modulus value $\mathrm{E}=4.5 \pm 0.2 \mathrm{MPa}$. The antibacterial effect depends on the nanoparticles concentration in collagen film, being more evident against Gram-positive bacteria (E. coli) than Gram positive ones (S. aureus). Moreover, the 
antioxidant capacity monitored by CUPRAC assay, indicated a synergic effect of chitosan matrix and propolis extract, incorporated in collagen films.

\section{References}

1.TRONCl, G., Advanced Textiles for Wound Care, $2^{\text {nd }}$ Edition, Woodhead Publishing, 2019, Chapter 13, p. 363-389.

2.FONSECA, J.M., ALSINA, A. M., FRANCESCA, R., Biochim. Biophys. Acta Biomembr., 1279, 1996, p. 259-265.

3.CHATTOPADHYAY, S., RAINES, R.T., Biopolymers, 101, 2014, p. 821833.

4.DUMITRU, M.G., GANESCU, A., DABULEANU, I., Mat. Plast., 53, no.3, 2016, p. 414-418.

5.YANNAS, I.; BURKE, J.; ORGILL, D.; SKRABUT, E. Science 1982, 215,174-176.

6.SHETTIGAR, U.R., J AGANNATHAN, R., NATARAJAN, R., Artif. Organs, 6, nr. 3, 1982, p. 256-260.

7.VOSS, G.T., GULARTE, M.S., VOGT, A.G., GIONGO, J.L., VAUCHER, R.A., ECHENIQUE, J.V.Z., SOARES, M.P., LUCHESE, C., WILHELM, E.A., FAJ ARDO, A.R., Int. J. Pharm., 2018, doi.org/10.1016/j.ijpharm. 2018.10.009.

8.RATIU, C., BROCKS, M., COSTEA, C., MOLDOVAN, L., CAVALU, S., Appl. Sci., 9, 2019, 1035, doi:10.3390/app9051035.

9.AGRAWAL, P., SONI, S., MITTAL, G., BHATNAGAR, A., Int. J. Low. Extr. Wound, 13, 2014, p. 180-190.

10.WANG, J. ., ZENG, Z.W., XIAO, R.Z., et al., Int. J. Nanomedicine, 6, 2011, 765-74.

11.PENICHE, H., PENICHE, C., Polymer Int., 60, 2011, p. 883-889.

12.FREIRES, I.A., DE ALENCAR, S.M., ROSALEN, P.L., 2016. A pharmacological perspective on the use of Brazilian Red Propolis and its isolated compounds against human diseases. Eur. J. Med. Chem. 110, 267-279.

13.OLIVEIRA, R.N., MANCINI, M.C., SALLESDE OLIVEIRA, F.C., PASSOS, T.M., QUILTY, B., DA SILVA MOREIRA THIRE, R.M., MCGUINNESS, G.B., Materia, 21, nr.3, 2016, pp. 767- 779.

14.ZAHA, D.C., KISS, R., HEGEDUS, C., GESZTELY, R., BOMBICZ, M., MURESAN, M., PALLAG, A., ZRINYI, M., PALL, D., VESA, C.M., MICLE, O., BioMed Res. Int., 2019, https://doi.org/10.1155/2019/2510875.

15.ZAHA, D.C., BUNGAU, S., ALEYA, S., TIT, D.M.,VESA, C.M., POPA, A.R., PANTIS, C., MAGHIAR, O.A., BRATU, O.G., FURAU, C, MOLERIU, R.D., PETRE, I., ALEYA, L., Sci. Total Environ., 687, 2019, p.118-127. 16.MUNIN, A., EDWARDS-LÉVY, F., Pharmaceutics, 3, 2011, p. 793-829. 17.KUMARI, A., YADAV, S.K., PAKADE, Y.B., SINGH, B., YADAV, S.C., Colloids Surf. B Biointerfaces, 80, 2010, p.184-192.
18.CAVALU, S., BISBOACA, S., MATES, I. M., PASCA, P.M., LASLO, V., COSTEA, T., FRITEA, L., VICAS, S., Rev. Chim. (Bucharest), 69, no.12, 2018, p.3756-3760.

19.OLIVER, W.C., PHARR, G.M., J. Mater. Res., 7, 1992, p.1564-1583. 20.***Clinical and Laboratory Standards Institute: Performance standards for antimicrobial susceptibility testing. $20^{\text {th }}$ Informational supplement, CLSI document, 2010, M100-S20, PA, USA, Wayne.

21.APAK, R., GUCLU, K, DEMIRATA, B., OZYUREK, M., CELIK, S.E., BEKTATODLU, B., BERKER, K.I., OZYURT, D., Molecules, 12, 2007, p.1496-1547.

22.APAK, R., GUCLU, K., OZYUREK, M., CELIK, S.E., Microchim. Acta, 160,2008 , p. 413-419.

23. SICA DE TOLEDO, L.A., BAVATO, M.I., ROSSETO, H.C., CORTESI, R., BRUSCHI, M.L., Braz. J. Pharm. Sci., 51, nr. 4, 2015, p. 847-859. 24.DA SILVA BARUD, H., DE ARAUJO JUNIOR, A.M., SASKA, S., MESTIERI, L. B., CAMPOS, J.A.D.B., DE FREITAS, R.M., FERREIRA, N.U., NASCIMENTO, A.P., MIGUEL, F.G., VAZ, M.M.O.L.L., BARIZON, E.A., MARQUELE-OLIVEIRA, F., GASPAR, A.M., RIBEIRO, S.J.L., BERRETTA, A.A., J. Evid. Based Complement. Alternat. Med., 2013, http://dx.doi.org/ 10.1155/2013/703024.

25.UNGUREANU, C., IONITA, D., BERTEANU, E., TCACENCO, L., ZUAV, A., DEMETRESCU, I., J. Braz. Chem. Soc., 26, nr. 3, 2015, p. 458-465. 26.LI, M., HAN, M., SUN, Y., HUA, Y., CHEN, G., ZHANG, L., Int. J. Biol. Macromol., 122, 2019, p.1120-1127.

27.AHMAD, M., NIRMAL, N.P., DANISH, M., CHUPROM, J., J AFARZEDEH, S., RSC Adv., 2016, 6, p. 82191-82204.

28.RHO, K.S., JEONG, L., LEE, G., SEO, B.-M., PARK, Y.J ., HONG, S.-D., ROH, S., CHO, J.J., PARK, W.H., AND MIN, B.-M., Biomaterials, 27, 2006, p.1452-1461.

29.STYLIANOU, A., YOVA, D., Mater. Sci. Eng. C, 33, 2013, p. 2947-2957. 30.POLK, S., SORI, N., THAYER, N., KEMPER, N., MAGHDOURI-WHITE, Y., BULYSHEVA, A.A., FRANCIS, M.P., Biofabrication, 10(4), 2018, doi:10.1088/1758-5090/aad7d0.

31.SIONKOWSKA, A., WISNIEWSKI, M., SKOPINSKA, J., POGGI, G.F., MARSANO, E., MAXWELL, C.A., WESS, T.J ., Polym. Degrad. Stab., 91, 2006, p. 3026-3032.

32.DA CRUZ, A.E.T., DA SILVA, M.C.D, etal., J . Pharmaceutical Analysis, 7, 2017, p. 280-287.

33.DE LIMA, G.G., DE SOUZA, R.O., BOZZI, A.D., POPLAWSKA, M.A., DEVINE, D.M., NUGENT, M.J.D, J. Pharm. Sci., 105, 2016, 1248e1257. 34.GALEOTTI, F., MACCARI, F., FACHINI, A., VOLPI, N., Foods, 7(3), 2018, p. 41. doi:10.3390/foods7030041

Manuscript received: 8.05 .2019 